\title{
Analysis of Uses and Metrology: an Experiment in Telecommunications by Satellite and Wireless Network Solution for Rural Areas
}

\author{
Fautrero Valérie, Fernandez Valérie and Puel Gilles \\ Télécom ParisTech/Université de Toulouse
}

France

\section{Introduction}

The TWISTER "Telecommunications by Satellite and Wireless Network Solution for Rural Areas" project $(2005 / 2007)$ is a response to the European Commission's call for tenders, dedicated to satellite solutions. It brings together a consortium of satellite operators (EADS Astrium, Aramisca, Eutelsat and the CNES) and demonstrates not only the determination of Europe to combat the "digital divide" but also its refusal to abandon an important market, which is essentially in the hands of American operators. The project involves numerous experimental sites in seven European countries (notably France, Spain and Poland). It was based on a wide-scale test. Twister offers high-speed access via satellite, often coupled with $\mathrm{Wi}-\mathrm{Fi}$, as well as related applications specific to rural needs, concerning agriculture, health, e-business, e-learning, etc.

\section{The research model}

\subsection{The research problem(s)}

The research problem revolves around one question: that of analysing the process of adoption and the prospects of wider deployment of technical systems. The question of the wider deployment of the technical systems concerns not only the analysis of learning mechanisms and the appropriation of technology, but also that of the impact/effects on the territories used in the experiment and of the interplay of the stakeholders.

The analysis of the couplings referred to below is based on the means chosen to achieve the objective. Four "variables" interact here: technical systems; applications; territories; and the level of expertise of users.

Technical systems are understood to mean the mixed "alternative" systems of high-speed Internet access proposed in the Twister project, namely satellite (collection and coverage) and Wi-Fi (coverage).

Applications are understood to mean the protocols (and therefore the related uses) used by the people taking part in the experiment during the period of the project. These include among others the Web, transfers, mail, instantaneous messaging and VoIP. 
Territories are understood to mean the experimental sites benefiting from the Twister project, and more specifically Tibiran-Jaunac, Lesponne/La Mongie (Haute-Pyrénées) for the qualitative part of the study, then the communes of Alpartir, Longas, Luesia, (13 in total, located in France, Spain and Poland).

Users are understood to mean the people benefiting from the service proposed within the framework of the Twister project. They have varying levels of ICT expertise: novices, regular users, experts.

These variables can be considered from the point of view of various couplings:

- focusing the analysis on the "applications/territories" coupling, in order to identify, for example, the variables explaining the adoption and appropriation of an application by a territory and the conditions necessary to ensure its effective transposition to other territories. A strong coupling between these two variables could reflect the wish of a local authority, responsible for territorial development, to put in place a structuring application: for example the deployment of health services as in Greece;

- the "applications/technical systems" coupling, in order to identify, for example, the attributes of the alternative technologies used, which might be an obstacle to the use of an application: problems of latency, sharing bandwidth in the case of use by communities, etc.). This coupling reflects whether or not the technical system is capable of supporting certain applications; for example, the satellite network system as deployed in Twister does not support applications such as VoIP, videoconferences, etc.;

- the "systems and territories" coupling: where the application plays the role of an intermediary variable in analysing the success factors of a technology, etc. A strong coupling reflects the dynamic created when a local authority decides to structure a territory around a technical system, such as covering non-ADSL enabled areas;

- the "technical systems and users" coupling: in order to identify, for example, the process of the adoption of a system by users. A strong coupling between these two variables could reflect the wish of users to appropriate technologies in order to have high-speed access.

\subsection{Research premises}

This research is based on the examination of pilot projects deploying alternative technologies which ran in France between 2005 and 2007, observed longitudinally using a qualitative approach (Yin, 2003). The "alternative" technologies pilot projects involved a large number of participants with differing rationalities: the State, local authorities, operators, components manufacturers, users, researchers, etc. How can we understand the complex dynamic interactions which occurred between these various participants in the pilot projects?

In economic literature, experimentation can be defined as a scientific research method, used to test products and services (in a laboratory or in the field), with a view to obtaining strategic information (technical, social or economic), before competitors. Its main interest is its force of persuasion in comparison with other types of studies, but its high cost means that only a small sample is used ${ }^{1}$. The demand for information increases when a new, untested product is

1 Encyclopaedia of sociology, 2000, p.887-890 
launched on a market (Grossman and others, 1977). Thus, companies that enter a new, unfamiliar market want information. They find themselves facing a situation where the level of demand is unknown and experimentation can help them to improve their market knowledge. For Bolton and Harris (1999), experimentation can lead to a strategic game between players, as a result of the information garnered. The player that puts in place such a system will obtain data which will, over time (this is variable), finish in the public domain, where it will be accessible to its competitors. Leach and Madhavan (1993) explain that in the short term, experimentation is expensive. But it can be cost-effective in a dynamic context where a large amount of information can be profitable for future actions.

In the telecommunications sector, the dual nature of experimentation makes it an important strategic tool, since experimentation is at the same time a research method, a test method (yielding information) and a defined territory. The opportunities for action, in an uncertain environment, are thus twofold: the deployment of such systems helps to shape an overall strategy with utilisation, service and product tests; the geographic proximity to potential customers enables the creation of demand and a market, as well as greater notoriety. In France, the Act on Confidence in the Digital Economy (of 21 June 2004) now allows local authorities to establish, in their territory, both passive and active infrastructures and to make them available to telecoms operators or users of independent networks. The first actions of the authorities involved local experiments. The persistence of areas not covered by ADSL (the citizens concerned demanded solutions) and the arrival of "new2" high-speed technologies on a "liberalised" market, led the State to develop these technologies. Thus an "alternative technologies" support fund was made available between 2003 and 2005 which presents, through an "organising" vision (Swanson and Ramiller, 1997), the latter as "credible". This credibility, which can be broken down into three aspects: operability, quality of service (performance, security and bandwidth) and cost, seem to vary considerably according to the territorial and time dimensions.

$\mathrm{Wi}-\mathrm{Fi}$ technology is sensitive to the environment in which it is deployed: the presence of natural obstacles (trees, climate or topography) or imposing human constructions (buildings) can disrupt the propagation of waves (outdoors) and necessitate an investment in additional equipment to facilitate the latter or to fell trees that are sometimes over a hundred years old, etc. Coupled with satellite, it conveys the limits intrinsic in the latter technology: latency period, sharing bandwidth.

The market, as a social construction, is shaped by the environmental context and the political, economic and technological issues of the stakeholders involved. Therefore, the emergence, commercialisation and adoption of a technology are the fruit of negotiations involving private-sector stakeholders (operators, associations, components manufacturers, ISPs, etc.) and public-sector stakeholders (the State, local authorities, etc.): for example, the development of a technology or a technical standard supposes that the public authorities (through their standardisation bodies and their legislators) have authorised their use. The use of these alternative technologies, not always equivalent to the standard, seems consequently to have been the result of lobbying actions and the work of pressure groups. In the case of $\mathrm{Wi}-\mathrm{Fi}$, the presence of geeks grouped together in communities in a region, and their enthusiasm for this technology and its ideology of sharing, is a significant factor in the roll-out of wireless networks. In the case of "satellite" technology, the partnership between

\footnotetext{
2 Some technologies have existed for many years, such as Wi-Fi (with different uses) and PLC (kept on the fringes of the market for some time - according to some observers for political reasons).
} 
public-sector stakeholders (in particular locally elected representatives in municipalities located in white spaces), satellite and wireless operators led to the roll-out of "satellite/Wi$\mathrm{Fi}^{\prime \prime}$ type high-speed solutions in mountainous or isolated areas.

The question of alternative technologies is therefore linked to the surrounding territorial and environmental context. Alternative technologies, as well as the interaction of pressure groups (relevant groups) are regionalised and bring together several levels (national, local, etc.) of stakeholders and negotiations. The "spirit of technology" (Swanson and Ramiller, 1997), which makes it possible to give a meaning and a collective image to the latter, is a joint venture in a specific socio-institutional context, the subject of negotiations, where the public authorities, users and industrialists-operators interact. From this analytical standpoint, technology is at the same time both a material artefact and a social object. "Users" in the same way as the other stakeholders participate in the social construction of technologies which have a "flexible nature" (Orlikowski, 1992). The interpretative flexibility varies according to the groups involved which may have a different perception of the same technology. Bijker (1995) mobilises the concept of "relevant social groups", categories of stakeholders that have an influence on the development of a technology.

The territories differ (socially, culturally and economically) and do not have the same social capital. We can assume that the types of usage and technology habits differ according to the interactions between the elements composing the territorial systems. However, each case is not unique and falls within the scope of a typical ideal. Therefore, we have observed territorial models (see above), which comply with a series of recurring types of behaviour and which, accordingly, may prove essential not only for understanding the world but also for the implementation of technical systems and public or private actions within the framework of territorial development.

The quantitative and qualitative studies of these questions may provide further ideas to be explored or responses on which appropriate action can be based: which jobs are "lost" as a result of the deployment of technology (which intermediaries?) and which jobs are developed or created? Where are they located?

Different replies to these questions may admittedly correspond to models of territorial contexts, but also possibly to territorial development choices. The nature and quality of the services deployed by the technical system will be an important parameter for analysing the results: developing a local granite production system or agritourism gives rise to different practices and territorial links.

However, the historical process will be equally pertinent for our analysis: there are moments in the deployment of technology (phase of appropriation, intensification of types of usage per level, etc.), which can explain differences.

\section{Methodology and metrics}

This survey relies more particularly on two partners of the Twister project (mentioned in the continuation of the document): EADS Astrium, co-ordinator and responsible for the technical supervision of the satellite/Wi-Fi networks and Aramiska, then Ouranos (from September 2006), the Internet satellite access service provider.

Our study covers the period from June 2005 to December 2006. Initially, preliminary work was necessary to delimit the territories covered by the Twister project. This first phase led us to examine a selection of 13 sites deployed in France, Spain and Poland. Geographical, 
demographic and economic data were collected by way of Internet searches, supplemented by data provided by INSEE and its Spanish counterpart (INE) and finally the site dossiers provided by the local project leaders or co-ordinators.

At this stage, an initial typology comprising two categories of territories was presented at a meeting (end of August 2005) to EADS Astrium:

- the territories constructed by the services within the framework of the Twister project. Certain territories benefit from specific services and applications, in the areas of agriculture (in France, in the Allier, Dordogne and Charente), e-business (in Poland, in Suwalki, Hanzca, Lajski and Warsaw, etc.). The Twister typology of the sites for certain applications (e-business, education, agriculture, health, etc.) is the somewhat artificial result of the construction of the project. However, a more precise analysis would undoubtedly reveal similarities between the territories in Poland, Spain, France and Greece (territories with geographically isolated communities);

- community territories, that is to say territories benefiting from Internet access shared between the people taking part in the experiment in the territory; these may be "open", having a certain attractiveness in terms of population, tourism, culture, or "closed", that is to say suffering from their geographical isolation.

This typological interpretation enabled us to lay the foundation for a more detailed analysis of certain sites. The objective of the second phase, based essentially on quantitative data (provided by EADS Astrium), was to detect the usage processes of the people taking part in the experiment and/or of the sites, so as to be able to propose a more precise typology.

The data provided by EADS Astrium can be broken down as follows:

- monthly EADS Astrium data, in the form of charts:

- In and Out traffic by site (Upload and Download),

- breakdown of traffic consumed by each category of users ;

- the most used protocols for each site,

- the most used protocols for each category of users ;

- $\quad$ statistical reports sent to the co-ordinators of the first six DPZ sites, Cemagref Sites; University of Warsaw, Montaignac, Luesia, Francescas, Alpartir;

- Aramiska data: monthly aggregated In + Out traffic per site (namely, the aggregation of Up- and Downloads).

This data enabled us to test certain assumptions:

- $\quad$ the territory (through its characteristics) may be a variable, which explains certain specific means of appropriation;

- the type of user (institution, residential, etc.) may explain the development of certain types of use (e.g. peer to peer);

- $\quad$ the consumption of users may be linked to the days of the week.

The data were obtained from several sources (Aramiska, EADS Astrium), each using different collection methods, and relate to different periods (the projects were not put in place at the same time). For reasons of accuracy and in order to avoid approximations as much as possible, EADS Astrium provided us with raw data relating to the aforementioned charts (see Excel listing). We have therefore reprocessed the statistics in Excel and produced charts, in order to obtain results that are as objective as possible and overcome the difficulty of comparing projects, which were initiated at different periods. Thus, to supplement the charts representing the experiments according to the month of the year (e.g. May 2005, June 
2005 , etc.), but not taking into consideration the temporality of the projects, our charts represent the projects at the same stage of their deployment (Month 1, Month 2, etc.).

At the end of this phase, we selected the sites for the qualitative survey in order to crossrefer the results with the quantitative data.

We selected the communes of Lesponne, La Mongie and Tibiran-Jaunac (Hautes-Pyrénées). Our selection was based, on the one hand, on the deployment schedule for the experiments (it involved examining projects, which have been in place for a sufficient period of time for the people taking part in the experiment to have had time to use the system) and, on the other hand, the opinion of our partner (we had to be sure that the technical installation period had been completed and that there were no specific technical problems affecting the correct use of the system).

In order to delimit more closely the experimental sites, and to get to know and understand as closely as possible the people taking part in the experiment, and their types of usage, our research was based on a series of face-to-face interviews with users, local administrators and administrative managers. The interviews were conducted in April 2006 in Lesponne, La Mongie and in December 2006 in Tibiran-Jaunac.

The interview guide used, adapted according to the three aforementioned categories of interviewees, comprised three main parts: presentation of the interviewee, presentation of the territory and opinions on the experimentation (see appendix).

\subsection{The limits of the work}

However, several factors have to be taken into consideration in any analysis of the results obtained:

- the occasional lack of data: the (traffic) monitoring data was affected by several technical failures. These failures affected almost all the sites studied, which had an adverse effect on the "correct" interpretation of the statistics;

- the a priori selection of the sites given that our work is based only on the information provided. The sites studied were therefore selected de facto;

- the recent implementation of the experiment and therefore limited basis of assessment. Our assessment of changes in use needs to be seen in the context of the recent deployment of the systems. They were deployed less than six months earlier;

- $\quad$ the data is collected by volume (MB). Our analysis is therefore based on the actual traffic consumed by the people taking part in the experiment. Accordingly, types of usage requiring little traffic (for example, e-mails) are under-represented;

- finally, we lack information on the territorial ecology of the various sites and on the people taking part in the experiment (for example, their professional and personal activities, etc.). ${ }^{3}$

Questionnaires and face-to-face interviews are the only way of gaining a better understanding of actual uses.

\footnotetext{
${ }^{3}$ Information on the profile of users (professional or residential), as well as the age profiles for certain users (DPZ) was available.
} 


\section{The quantitative part}

\subsection{Bandwidth consumption}

The aim of the chart 1 is to correct the over- or under-representation of certain sites, which have a large number or few people taking part in the experiment. The aim, therefore, is to look at the average consumption per user of each of the sites on a monthly basis.

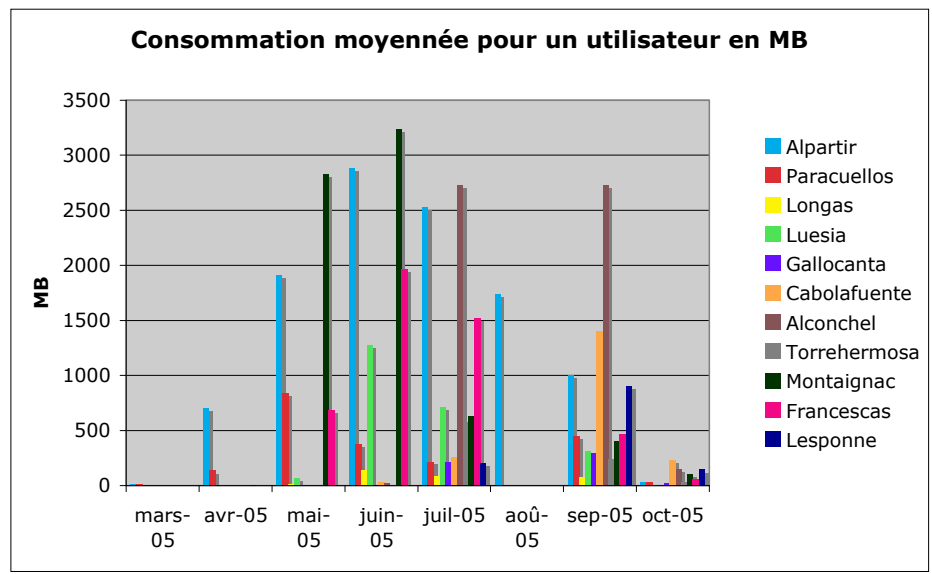

Fig. 1. Average consumption of bandwidth per user

Consumption seems to follow in time an inverted " $U$ " curve. We can therefore hypothesise that it is a normal law, which reoccurs often in the learning process.

Several sites stand out: Alpartir, Francescas, Montaignac and Alconchel. The sample of people taking part in the experiment in Alpartir includes a significant number of students (the site is near a college offering ICT courses ${ }^{4}$ ), and in Francescas and Montaignac a not insignificant percentage of companies. However, at this stage of our research, there are no specific reasons that explain the consumption of Alconchel.

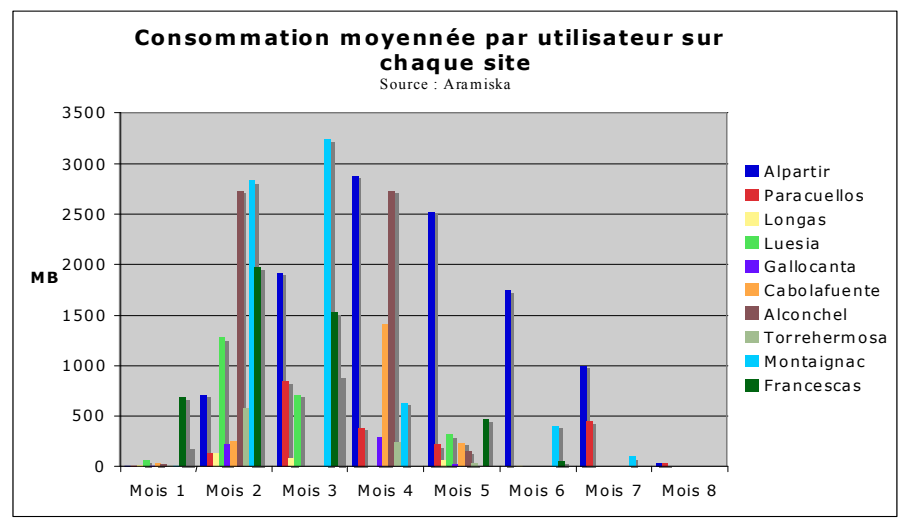

Fig. 2. Average consumption and stage of deployment

\footnotetext{
4 Which seems to confirm the importance of the sociological variable on the profile of users in our analysis.
} 
Although the graph allows the different sites to be viewed simultaneously, it is to be noted that the sites are not at the same stage of deployment. For example, the experiment started in Cabolafuente in June 2005, consumption increased in July, was at its highest in September and then declined in October. On the other hand, Luesia started earlier and peaked earlier. The "time" dimension, as it is represented, makes any comparison difficult. The four sites that stand out must be treated with circumspection. However, we can consider that traffic has not yet stabilised.

The aim of the chart 2 is to compare the average consumption of one user on each of the sites, at the same stage of deployment of the system. For these sites, the duration of the experiment is between three and six months. The inverted " $U$ " curve (or normal law) is confirmed. In the first month(s), consumption is low. This period is followed by a strong increase in traffic then, more or less stable, consumption declines at differing rates. Alpartir illustrates perfectly this curve.

We can therefore put forward the hypothesis that the people taking part in the experiment need time to adapt and familiarise themselves with the connection, and that their consumption is important during the initial part of the experiment and that their interest seems to decline subsequently. Or is it their use of the connection which changes? Greater use of the Web? More e-mails? It must be borne in mind that the data are in $\mathrm{MB}$ and that the representation of types of usage requiring little traffic is difficult ${ }^{5}$.

\subsection{Types of usage}

During the period of the experiment, EADS Astrium analysed the most used network protocols, by category of users per site and for all the sites. The traffic consumed for each of the protocols was then aggregated by type of usage. Based on that analysis, 10 main types of usage were determined via the related protocols. The following table shows the types of usage and their related protocols:

\begin{tabular}{|l|l|}
\hline Web Browsing & HTTP, HTTPS, NNTP-TCP \\
\hline File Transfer & $\begin{array}{l}\text { FTP, TFTP, NETBIOS-IP, NFS, SYSLOG, PRINTER, PRINT-SRV, RCP, } \\
\text { SUNRCP, CMD }\end{array}$ \\
\hline Mail & POP, SMTP, MS Exchange, IMAPS, CCMAIL, LOTUS-NOTES \\
\hline Online Messaging & MSN Messenger, AOL/ICQ, Yahoo, IRC \\
\hline Admin \& Supervision & SNMP, TELNET, etc. \\
\hline Online Gaming & COUNTERSTRIKE, MSN GAME, NEED FOR SPEED, etc. \\
\hline Peer To Peer & $\begin{array}{l}\text { KAZAA, EDONKEY, GNUTELLA, BitTorrent, WINMX, OVERNET, } \\
\text { Soulseek, etc. }\end{array}$ \\
\hline $\begin{array}{l}\text { Real Time Stream } \\
\text { Video \& Audio }\end{array}$ & RTSP, Msplayer, REALAUDIO, NETSHOW, Winamp, etc. \\
\hline VoIP & SKYPE, MGCP, H323, T120, VOCALTEC-IPHONE, PHILIPS-VC-TCP \\
\hline All Others & $\begin{array}{l}\text { All Others: Network Infrastructure (ARP, RIP, DNS etc.)+Unidentified } \\
\text { protocols ports }\end{array}$ \\
\hline
\end{tabular}

Table 1. Types of usage and their related protocols

\footnotetext{
${ }^{5}$ A comparison of these data with data relating similar systems (ADSL type) would undoubtedly be interesting.
} 
As a result of the important share of the "Others" category on certain sites, discussions were held with EADS Astrium in order to try and identify the types of usage falling within that category. In fact $80 \%$ of this category corresponds to a P2P activity. The chart integrates the transfer of the $80 \%$ of "Others" to the P2P category.

In order to identify the types of user behaviour, we have compared average uses (as a percentage) by site. The table 2 highlights the average (as a percentage and over the duration of the experiment for each site) of the sites by category of usage and the overall average per type of usage (in yellow).

\begin{tabular}{|c|c|c|c|c|c|c|c|c|c|}
\hline Site & Web & $\begin{array}{c}\text { File } \\
\text { transfert }\end{array}$ & Mail & $\begin{array}{l}\text { On line } \\
\text { Message }\end{array}$ & $\begin{array}{c}\text { On } \\
\text { line } \\
\text { Game }\end{array}$ & $\mathrm{P} 2 \mathrm{P}$ & Streaming & Voip & $\begin{array}{c}20 \% \\
\text { Othe } \\
\text { rs }\end{array}$ \\
\hline Alpartir & 34 & 5 & 0 & 0 & 0 & 48 & 1 & 0 & 11 \\
\hline Alconchel & 27 & 20 & 0 & 0 & 0 & 41 & 0 & 2 & 10 \\
\hline Galloconta & 48 & 0 & 1 & 0 & 2 & 38 & 1 & 0 & 9 \\
\hline Montaignac & 10 & 9 & 2 & 0 & 0 & 64 & 1 & 0 & 13 \\
\hline Francescas & 66 & 20 & 1 & 0 & 0 & 5 & 5 & 0 & 1 \\
\hline Cabolafuente & 54 & 9 & 0 & 0 & 0 & 34 & 1 & 0 & 2 \\
\hline Luesia & 63 & 1 & 2 & 1 & 0 & 14 & 17 & 0 & 3 \\
\hline Torrehermosa & 59 & 1 & 0 & 0 & 0 & 30 & 3 & 0 & 7 \\
\hline Longas & 49 & 2 & 0 & 0 & 0 & 42 & 2 & 0 & 5 \\
\hline Paracuellos & 55 & 2 & 0 & 1 & 0 & 37 & 4 & 0 & 2 \\
\hline Average & 49 & 5 & 0 & 0 & 0 & 35 & 4 & 0 & 6 \\
\hline
\end{tabular}

Table 2. Average by category of usage by sites

The main uses are the Web and P2P. Together they represent approximately $80 \%$ (aggregated) of the traffic.

The percentages above the general average for the type of usage are marked in black. This highlights three groups of user behaviour:

- those with above average use of P2P: Gallocanta, Alpartir and Alconchel and Montaignac;

- $\quad$ those with above average use of the Web: Cabolafuente, Luesia and Torrehermosa and Francescas;

- $\quad$ those with above average use of both: Paracuellos and Longas 


\subsection{Conclusions on this phase}

This analysis raises numerous questions. The data collected are expressed in volume (MB). It is therefore the traffic which is studied. Types of usage requiring little traffic are accordingly under-represented in the charts. In addition, the analysis is limited by the "time" dimension. The 13 sites were deployed only recently (less than six months earlier) and our results must be seen in the context of the limited duration of the experiment.

Accordingly, we added a qualitative phase to our research, based on interviews, in order to ascertain more accurately the actual types of usage.

In order to implement this new phase in our research we selected two sites: Lesponne/La Mongie and Tibiran-Jaunac (Hautes-Pyrénées).

\section{The qualitative part of our analysis}

\subsection{The Lesponne and La Mongie experiment}

The experiment took place from July 2005 in Lesponne and from October 2005 in La Mongie. In La Mongie, ADSL arrived in October 2005, following the signature of the innovative department's charter of France Télécom by the Hautes-Pyrénées department. The commune of La Mongie, included in France Télécom's deployment schedule, was connected more rapidly than initially planned. The operator accelerated the procedure.

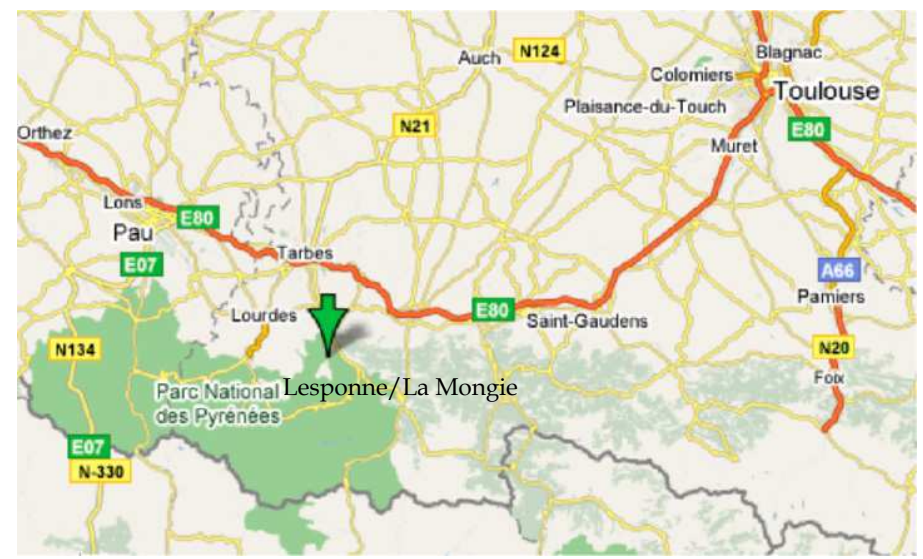

Fig. 3. Localization of Lesponne/La Mongie source Google map

The valley of Lesponne (located in the Hautes-Pyrénées department) is a non-enabled area for mobile telephones and high-speed access, and for certain people, not having high-speed Internet access is perceived as an intolerable disadvantage.

The people taking part in the experiment in Lesponne are connected to two networks:

- the first, in the centre of the village connects directly the town hall and the school via satellite, business people (self-employed people, teleworkers, and an innrestaurant) and three private individuals, thanks to a Wi-Fi relay installed on the church steeple;

- the second network is dedicated to the hotel resort of Ramonjuan which provides its guests with Wi-Fi access via a satellite connection. 


\subsubsection{Proposed uses}

When the experiment was put in place in La Mongie, a series of high-speed services dedicated to mountain-related businesses and activities were planned: telemedicine, skirelated traumatology via videophone, etc. The administrative and medical centres intended to use the connection to meet their own needs and then to offer, on the one hand, access to tourists and, on the other hand, for telediagnoses with Rangueil and Purpan in Toulouse. However, the ADSL connection was installed at the end of 2005 and the bankruptcy of Aramiska, which occurred one and a half months after the start of the experiment, delayed initiatives and reflection on possible uses. This interruption in service (lasting 15 days in February 2006) did not make matters easier, but one of the reasons was the lack of involvement of the local authorities in these service projects.

\subsubsection{Types of usage and satisfaction with the experimental system}

The experimental system does not seem to behave in exactly the same way as ADSL technology, which the majority of people taking part in the experiment have already used, at a friend's place or at work, etc. ${ }^{6}$.

On an everyday basis, the basic types of usage (searches, mail, browsing, etc.) have not given rise to any special problems. The types of usage of certain people taking part in the experiment have even developed, searches, online games, online shopping, managing Internet sites, etc. but they have all kept their old subscription and have used it several times (at the time of system failures, etc.). The Internet has replaced certain physical journeys to Tarbes (approximately $60 \mathrm{~km}$ away).

However, certain types of usage, which require more bandwidth, such as voice over IP (Skype), the use of instantaneous messaging software (MSN type voice and image) have apparently caused certain problems7. It appears that "synchronisation gaps" make videoconferences impossible. The signal is seen as too weak and the speed insufficient. However, the hotel resort of Ramonjuan is planning to build a conference room (with a movable amphitheatre) equipped with a videoconference installation. This installation would enable videoconferences to be organised, as well as live training sessions, on the Internet, during seminars. For the Ramonjuan hotel resort, the Internet plays an important role in developing its activities. Most of its estimates are sent by the Internet, some $75 \%$ of reservations and communications with guests are made by e-mail, and a number of seminars have been organised to take advantage of the Wi-Fi connection. Guests consider the quality of the connection to be good. Moreover, guests have been pleasantly surprised to have such a connection in the valley. Offering Wi-Fi access to guests is seen as a competitive advantage compared with other hotel resorts.

\footnotetext{
${ }^{6}$ It would be interesting to have data on the way in which ADSL behaves in terms of deploying technology.

7 The satellite technical system was not designed to support this type of application and users were informed of this during the advanced Twister training they received at the start of the experiment. However, perhaps we should see this as reflecting a lack of information given to the users regarding the limits of the system used in the experiment.
} 
The people taking part in the experiment consider that they are very fortunate to have highspeed Internet access. They are very satisfied with the service and the fact that it is free is considered as adequate compensation for the frequent technical incidents.

Interest in the experiment has increased over time. Several people have asked to join the project.

M. C.: co-ordinator in Lesponne.

Co-ordinator and technical intermediary between EADS Astrium and the people taking part in the experiment in Lesponne, M. C. also teaches IT at the school, on the three stations connected to the Twister system. Trained as a graphic designer and formerly an emergency physician, he has important professional needs and is passionately interested in high-speed access.

His main professional activity consists in creating and updating Internet sites. Highspeed access enables him to work from home as a teleworker. He has noted several differences in the use of the system in comparison to ADSL technology. With ADSL, pages are displayed progressively (from top to bottom). A blank page is displayed, and then the full page is displayed all at once. In addition, transfers take longer with the satellite system. Therefore, when he wants to modify the Internet pages of a site, the modifications do not appear, because of the cache.

Skype does not work. Sound and video do not work. The MSN connection is often lost. Words are not synchronised, as a result of the problem of data sent and received via the cache. On the other hand, there are no problems for basic types of usages.

Although he has to deal with all the problems of the people taking part in the experiment (which means that he has to be reactive and a lot of his time is taken up resolving problems), he is pleased to have high-speed access.

Interview conducted on 6 April 2006

"Chez G." inn, Lesponne: the Internet "s a work tool".

The owners of the inn moved to Lesponne in 2003. They have two Internet sites devoted to their professional activities: one to the inn itself, with online reservations, which they set up when they arrived in 2003. The calculate that $80 \%$ of the inn's reservations are made via the Internet site and consider that the site is a very good means of communication and helps to enhance the inn's visibility beyond the local area. Numerous Anglo-Saxons visit the region and find an online service easier to understand and use. The second Internet site, devoted to their mountain guide activity, has existed since 2001. It gives details of prices, availability and other information, updated on daily basis, useful for tourists.

Since the beginning of the experiment, their types of usage have developed and increased: a large number of searches (for their children's schoolwork, news, etc.), online games, etc. They now spend more time connected to the Internet, but do not consider that there has been any substitution.

Interview conducted on 6 April 2006

${ }^{8}$ The satellite system was designed for basic Internet services, not to support Skype or MSN. 


\subsubsection{Problems perceived by users}

The service has been subject to numerous incidents and interruptions. "Even if we do not pay for it, it still needs to work". "It must work properly, otherwise we need ADSL."

For most users, the system put in place is not perceived as an experiment or a test, but as a permanent way of having high-speed access (because it is often presented as such). Therefore, the problems encountered can provoke strong reactions, especially when the failures are too frequent, despite the fact that access is free.

Four types of problems/drawbacks have been encountered: technical problems, a lack of information and a failure to take on board the views of the people taking part in the experiment, the conflict between bandwidth and data security.

Technical problems have a variety of causes. It seems that they occur mainly during the weekend, from Saturday, because of the types of usage developed (MSN and downloading files) by the children of those taking part in the experiment.

The satellite dish is easily impaired by snow (even with little snow) and simple snowflakes or drops of water can interrupt the Internet connection. A solution is possible, but was not "taken into account" within the framework of the experiment. "This would involve investing in a protective system, the cost of which would vary, that is to say either a resistant cone or a ventilation system". Therefore a tree branch or a broom is used to clear the snow from the satellite dish, which is fixed at a height that makes it accessible for this purpose.

This problem has led to other problems, because "everyone has tinkered with the connection", giving rise to numerous individual "parameterization" problems.

Finally, numerous elements that cause failures and uncertainties need to be managed by the site co-ordinator: installation, personal connections, equipment, human handling, etc., making the task delicate and difficult. That is his role as defined by the Twister system. In this regard, a lack of information, the co-ordinator's level of expertise and availability can create problems.

Users are critical of what they perceive as a lack of communication and information provided within the framework of the experiment:

- technical failures and the means to be put in place to resolve them;

- the management of exceptional events. The bankruptcy of Aramiska raised concerns and questions, to which no answers were given ${ }^{9}$;

- the installation of the equipment and material by technicians. The system was not co-constructed with the users, resulting in certain shortcomings in the installation. For example, apparently, connection sockets were installed "anywhere" (sensitive places, with a lot of comings and goings, for example, next to a door). "And these are very fragile, sensitive";

- At the Ramonjuan hotel resort, Wi-Fi is available free of charge to guests, but the system chosen, within the framework of the experiment, is based on the use of vouchers. A connection to the network requires a code composed of a ten letters and digits (given by the hotel), a login and a password. This is valid for one hour or one day depending on the voucher chosen. However, when the computer switches to standby mode, users need to recommence the identification system. This can be

\footnotetext{
${ }^{9}$ It is to be noted that the bankruptcy of Aramiska resulting in the service being interrupted for "only" 15 days.
} 
a constraint given that the connection is free and people attending seminars stay at the hotel for several days ${ }^{10}$.

There have been bandwidth conflicts between the people taking part in the experiment in Lesponne. The downloading of MP3 (at the beginning) was one of the causes of problems of connections and bandwidth sharing. To resolve this excessive use, the co-ordinator discussed the issue with users to raise their awareness of the problem. He "spread the word" and the problem was solved.

Finally, the security of data on the Wi-Fi network was deemed inadequate.

\subsubsection{Resolving the problems}

Three types of behaviour ${ }^{11}$ were identified to resolve the failures and losses of connection, according to their "attachment" to the connection:

- the individual who has Wi-Fi access but whose use remains occasional or optional: this type of user lets things take their course and waits for the problem to solve itself. During this time (s)he uses the public switched telephone network (PSTN);

- $\quad$ the individual who has Wi-Fi access: this user unplugs and reconnects his modem. If the failure persists, he calls the co-ordinator, either to come and note the failure and try and solve it, or to call EADS Astrium (the co-ordinator is the direct contact person);

- the co-ordinator or the person in whose home the satellite dish in installed: he removes snow in the event of problems, irrespective of the time of day, and often helps the other people taking part in the experiment when they have problems.

During the period of the experiment, irrespective of the initial level of awareness of the users, most of them acquired rare skills, inherent in this technology, to resolve problems involving a loss of connection ${ }^{12}$.

\subsubsection{The future prospects}

Although price information (on the proposed cost at the end of the experiment) was communicated in October 2006 when the sites in question were switched to a Eutelsat solution after the second bankruptcy, this time that of the operator Ouranos, users complained about a certain vagueness. The community of communes could intervene and finance part of the installations. High-speed Internet access has become indispensable for some of the people taking part in the experiment, who have even declared that they will move from the area if high-speed access does not become permanent.

In the Ramonjuan hotel resort, the end of the experiment has not yet been really anticipated (but several diversification attempts at the hotel resort have failed), the question of the cost has not been studied, but "it will not end there"13. Moreover, a consultant was

\footnotetext{
10 If all this information feedback is interesting, it is to be noted that it was not obtained during the project, but once the project was terminated. This sociological behaviour may seem specific to the context of the experiment.

${ }^{11}$ This behavioural typology suggests that the user profile is a variable in its own right of the model, in the same way as the system, the application and the territory.

12 It must be remembered, however, that TWISTER provided specific training for the local administrators as well as technical information for users.

${ }^{13}$ The words of the hotel's owner.
} 
commissioned by the CIDAP to carry out a market research study for the hotel resort. This study, which was carried out by a consultant from Toulouse and financed in part by the regional council, concluded in particular that there was no regional market for industrial seminars that would justify the deployment of a videoconference system.

In La Mongie, all the people taking part in the experiment switched to ADSL as soon as that technology was deployed in the resort, well before the end of the experiment. ADSL is a system which seems to "kill" any alternative solution, irrespective of its quality.

The list of people taking part in the experiment is closed, because of the speed proposed and the need for sharing as well as the equipment to be financed, but several structures and individuals would like to participate in the experiment: a restaurant owner, as well as two people who have recently moved to the area: an English teacher who wants to organise online language courses and a person who wants to organise martial arts videoconferences. This situation creates a certain amount of jealousy among those who are "excluded" from the experiment.

Despite the failures experienced by the people taking part in the experiment, it appears that the Twister solution is unanimously perceived very positively and interests a growing number of people who have recently settled in the valley. The absence of ADSL and the fact that the experimental system is free encourages people who have recently arrived in the area (English people, neo-rural residents, etc.) to try and participate in the project. However, there is a problem with the quality of service of the system for users having large bandwidth needs.

\subsection{The experiment in Tibiran-Jaunac}

Tibiran-Jaunac-Las Aribes, a commune in the Hautes-Pyrénées, has 249 inhabitants, including a retirement home with 62 residents. Its territory is very vast: the subscriber node is $8 \mathrm{~km}$ from the nearest telephone subscriber and $14 \mathrm{~km}$ from the furthest subscriber. Tibiran is a perennial non-covered area, which, according to the mayor, does not interest the operators and whose network is not maintained by France Télécom.

The majority of the commune's inhabitants are elderly and are from the farming sector. Active inhabitants work mainly in Tarbes and Toulouse. The development plans include a communal estate.

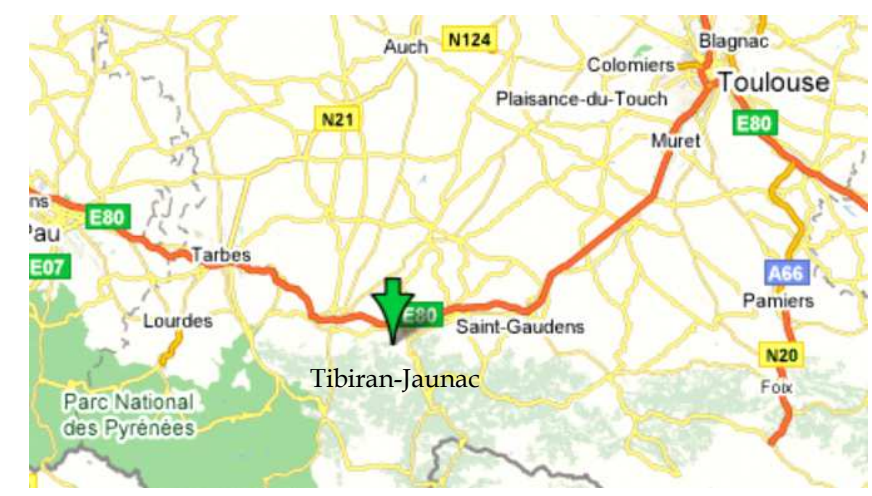

Fig. 4. Localization of Tiriban-Jaunac Source: Google map 


\subsubsection{The genesis of the project}

Local demand, composed of recently retired people and young people of school age, is strong. At the end of 2004 the mayor contacted France Télécom to connect the commune to ADSL. The operator considered that the commune was not eligible, but indicated that it could consider making a commercial offer if the commune financed the installation, at an estimated cost of $€ 300,000$.

There is still a strong demand within the commune and the mayor would like to find another cheaper solution. The project was then included in the Twister project at the end of 2005.

The mayor's personality and his ICT knowledge play a fundamental role in the high-speed project for the commune. He is familiar with the technology involved since he is seconded from the Interior Ministry to the ICT department of the Prefecture of the Hautes Pyrénées. The mayor decided, as soon as Tibiran was accepted as a Twister site, to put in place a veritable infrastructure policy for his territory by investing in a radio network to connect all the inhabitants.

\subsubsection{The needs and projects}

High-speed access is seen as a possible way of delivering more neighbourhood services to the commune's inhabitants:

- $\quad$ at the current time the town hall is open only on Saturdays: therefore the town hall intends to propose uses linked to the dematerialisation of procedures. It also wants to put in place an Internet access point, with three stations, linked to the town hall (training, etc.);

- the retirement home that provides medical care has considerable needs. These include, in particular, being able to connect to the local management system in Tarbes via a high-speed link; personal services are also planned (remote transmission, telediagnosis, etc.);

- $\quad$ since June 2006, it has been necessary to provide notaries public or purchasers of property with information regarding the commune and/or the risks related to the plot of land. The idea is to provide direct online access to such information;

- finally, the farm/inn present in the commune wants to develop Internet tools, such as an Internet site with online reservations.

\subsubsection{The use made of the experimental system and the problems encountered}

The system was deployed in Tibiran-Jaunac at the end of 2005. It connects the 12 people taking part in the experiment. The participants were selected by the mayor, based on the first applications, while trying to achieve a mix of ages and types of usage. Some participants were used to high-speed access, while others were primarily motivated by the geographical distance separating them from their families.

The installation of the Wi-Fi system required some trees, some of which were a hundred year old, to be pruned or chopped down. The owners had to be "pushed" to accept this sacrifice. Health concerns regarding the effects of Hertzien waves were also an obstacle. 
The town hall considered that the bandwidth of $1 \mathrm{Mb}$ allocated by EADS Astrium ${ }^{14}$ to all the people taking part in the experiment was less than the speed announced initially. No peer-topeer problems have been encountered. An intelligent bandwidth manager was installed to this end (the last usage allocated was peer-to-peer).

The system has been affected by numerous losses of connection, due in particular to the failure of Aramiska, whose role was taken over by Ouranos Networks and other service interruptions to the satellite network. In the case of persistent failures, EADS Astrium's hotline is contacted. This is the only means used. The Wi-Fi network functions correctly.

Mrs B.: a participant aged 70

Mrs B. is a keen user of IT and the Internet. She has had a computer since 2001 and uses it intensively. She connects to the Internet for several hours every day. She uses it to make numerous searches and to pursue her leisure activities: information on embroidery and consulting forums on the subject, looking up train timetables, use of Google Earth to see how places she has visited have changed, genealogy searches, sending photos and looking more closely into information read in "Micro hebdo", etc. She also uses Skype every day (with headphones and Webcam) to call her daughter in Toulon. For her, high-speed access is indispensable.

She does not shop online (fears regarding bank card security) but looks up information, makes her choice and sends a shopping list to her daughter who then buys the items in question for her on eBay or other online shopping sites.

Thanks to the Internet and its search facilities, she avoids certain physical journeys and saves on the cost of telephone calls and postage stamps.

Finally, the only problem which she encounters is the English vocabulary specific to IT. Her dictionary is incomplete.

Interview conducted on 7 December 2006

Mr C.: a regular Internet user

$\mathrm{Mr}$ C. works at the University of Toulouse and commutes every day to and from Tibiran. He has used high-speed access for his professional activities since 1999. The Internet enables him to carry out a large number of searches on his passions in various fields: astronomy (in his view the photos on the Internet are better than direct viewing via an astronomical telescope), archaeology, the daily news, to supplement the radio and written press, local weather forecasts, etc.

The Internet is a means of putting daily information into perspective and making readers more responsible. "With a stone, you can crack a nut, or the neighbour's head."

Alongside the searches, which he also carries out at work, he also sends e-mails and photos to his friends. He neither uses Internet telephony services nor online shopping sites. The Internet enables him to avoid having to do certain tasks physically (buying train tickets) but, on the other hand, has had the opposite effect (discovering a museum online then physically visiting the museum).

14 At the end of 2005, Aramiska (then Ouranos) provided the Tibiran site with a free access service of $2 \mathrm{Mbps} / 512 \mathrm{kbps}$. From October 2006, the speed was reduced to $1 \mathrm{Mbps} / 256 \mathrm{kbps}$. 
He has sometimes carried out searches to help neighbours who did not want to take part in the experiment, but who now want to be connected.

Interview conducted on 7 December 2006

\subsubsection{Assessment of the results of the experiment}

Certain positive elements have emerged. At the end of the experiment, Wi-Fi technology is seen as both reliable and perennial. Local demand has increased strongly. Over and above the hard core of 12 people taking part in the experiment, thanks to word of mouth 300 people are currently awaiting a high-speed connection. For the town hall, which has a project for a communal estate, high-speed access is important to attract and keep people in the commune. The neighbouring communes also want to be connected to Tibiran-Jaunac's high-speed network.

There are however certain negative points:

- frequent losses of connection;

- the latency time is seen as long: this is a user perception of the system's performance. The relation with the latency time caused by the satellite may seem hazardous without any further information;

- the current project (the Twister experiment with its time and financial limits) does not allow more people to be connected ${ }^{15}$;

- $\quad$ the Internet satellite service available on the market does not support VoIP and there is strong demand for the voice-data coupling, "at the current time the network is too poor";

- Wi-Fi nuisances (waves, old trees, leaves, etc.) have been important;

- $\quad$ the continuity of the system after the experiment was not envisaged in the project. It depends to a large extent on the mayor and his investment in Wi-Fi. Twister has contributed the satellite part.

\subsubsection{The future prospects}

Since December 2006, the commune has been fully Wi-Fi covered, thanks to 6 relays and one satellite access point. The whole of this infrastructure has been financed by the commune $(€ 50,000)$ and subsidised for the time being solely by the State. The Midi-Pyrénées region is planning a call for projects to which the commune must respond. To that end, it must establish that no tenders have been submitted in response to its call for tenders (in accordance with the LEN), but the context is experimental, which changes things somewhat. The departmental council has not yet been mobilised on the question but lobbying has started.

For the experiment to be transformed into a commercial offering at an affordable cost for inhabitants, an economic model must be found. There are two thresholds fixed by the satellite offering and the ADSL offering in cities (not more than $€ 3$ for $1 \mathrm{Mb}$ per subscriber). There is also a psychological appropriation threshold by the user (irrespective of the user's location and the technology used) of the Internet access service which is that of ADSL, in urban areas. Indication: "The $2 \mathrm{Mbs}$ satellite connection is $€ 700$ a month. For 30 users, the

15 The satellite technical system could connect more users, in exchange for a financial contribution. 
cost is acceptable, but it will not be feasible to amortize the equipment and it will be difficult to renew the technical equipment every four years."

The town hall is holding discussion with TDF for the installation of a $2 \mathrm{Mbs}$ SDSL link to replace the satellite access point (approximately $€ 400$ a month). The aim is to conclude a public service delegation contract on a leasing basis with an operator to operate the network. But the changeover is both difficult (the software and equipment used for the network are proprietary systems and it would therefore be difficult for an operator to use them) and urgent (the project ends at the beginning of February 2007).

"For the time being the transition from experimentation to a commercial operation would be counter-productive. There would be some dissatisfied people."

\subsection{Conclusion}

The provisional evaluation of the Twister projects is positive. The solutions meet the highspeed needs identified beforehand. The deployment of the experiment has stirred interest in the valley, with increasing demand (successful school courses, reflection on the creation of a public Internet space, etc.). As a result other people have expressed an interest in benefiting from this offering which is attractive because, on the one hand, the equipment and material are fully financed and installed and, on the other hand, the connection is offered free of charge throughout the experiment. Subsequently, the community of communes could finance part of the installations to help maintain the system on the territory on a permanent basis, confirming the existence on this territory of a true digital development project, through the deployment of a technical system.

Nevertheless, the deployment of ADSL is developing as well as its technology (Re ADSL, etc.), the progressive covering of the territory by standard technology is a threat to the experiment. The technical difficulties encountered by the people taking part in the experiment and Aramiska's bankruptcy have hindered the development of this technology. Finally, a problem of "governance" (lack of information, the fact that the technical system and the types of usage and services proposed were not co-constructed, etc.) was identified. The people taking part in the experiment want the circulation of information to be improved.

\section{Conclusion}

The research problem revolves around one question: that of analysing the process of adoption and the prospects of wider deployment of technical systems. The question of the wider deployment of the technical systems concerns not only the analysis of learning mechanisms and the appropriation of technology, but also that of the impact/effects on the territories used in the experiment and of the interplay of the stakeholders.

The analysis of the couplings referred to below is based on the means chosen to achieve the objective. Four "variables" interact here (technical systems; applications; territories and users) and can be considered from the point of view of various couplings:

the "applications/territories" coupling, in order to identify, for example, the variables explaining the adoption and appropriation of an application by a territory and the conditions necessary to ensure its effective transposition to other territories; 
the "applications/technical systems" coupling, in order to identify, for example, the attributes of the alternative technologies used, which might be an obstacle to the use of an application: problems of latency, sharing bandwidth in the case of use by communities, etc.); the "systems and territories" coupling: where the application plays the role of an intermediary variable in analysing the success factors of a technology, etc.;

the "technical systems and users" coupling: in order to identify, for example, the process of the adoption of a system by users.

Our analysis has enabled us to confirm the relevance of certain couplings of variables.

For the "applications-territories" coupling, certain territorial stakeholders want to develop more particularly structuring applications, such as, for example, e-administration services (for citizens), telemedicine (for retirement homers, ski resorts, etc.). However these projects are still on the drawing-board and have not been implemented. It seems that the first phase is to use the system and assess its reliability, credibility, etc., which is a key stage in the process of taking things further and actually implementing projects. However, satellite connections do not support certain uses for which there is now strong demand (basic uses are no longer enough. The interaction of the "applications-systems" coupling is in that case weak. However, interest in high-speed Internet access is not called into question. The "systems-users" coupling (through the appropriation process) and the "systems-territories" coupling (through the action of the local authorities) are very strong, confirming the major attraction of high-speed access.

Our assessment of the results of the experiment reveals certain negative elements.

1) problems regarding the quality of service in relation to types of usages, which can consume bandwidth or a demand that tends to replicate urban demand (success of VoIP);

2) a question of territorial governance: how to manage the sharing of bandwidth? Selfmanagement or a 'technical' solution (software but who decides what and according to which criteria?);

3) the choice of territories used in the experiment: depending on the strategies of operators and regulatory and technological developments, the number of so-called perennial noncovered is shrinking.

There seem to be two types of territories: the transitional non-covered territories where satellite technology coupled with Wi-Fi seems to be a good temporary solution; in such cases the operators are preparing the market for the arrival of France Télécom since the business model is not competitive in the case of the French market. This raises several questions: how to transform these transitional solutions into a financially feasible market for operators? How long can this transitional period last? What prices should be charged? Is it necessary for the public authorities to contribute funding? For the perennial non-covered territories, satellite technology can be a solution if it can solve the problems of quality of service (see above) and provide a more efficient response to user requirements (peer-to-peer, VoIP);

4) finally, the local stakeholders participating in the experiment have quickly identified a decisive element, which is a stumbling block to territorial development: support services. The communes involved are small territories, which have limited financial resources and have difficulty not only finding the necessary technical and human competences locally, but also recruiting a "support co-ordinator" for the development of ICT.

However, numerous positive elements have undoubtedly emerged from the experiment.

1) The deployment of technology on territories, which satisfies the objectives of the public authorities to bring rural territories into the information society. 
In France, the prevailing view favours the digital development of the territory and the deployment of high-speed access. This is confirmed by the numerous policies implemented and aids provided at the level of the European Commission (Plan i2010), the State (Plan $\mathrm{RE} / \mathrm{SO}$ 2007) and its calls for projects (DATAR), etc. This prescriptive approach helps to stimulate (while accentuating the feeling of exclusion in the territories concerned) the highspeed offering by the operators irrespective of their type. The LEN (2004) supports this movement;

2) the development of a market on these territories; are we not seeing the ADSL operators arrive after or during the experiment and capture users?

These high-speed projects can find themselves competing with and "abandoned" by the sudden arrival of standard technology on the territory. Indeed, numerous experiments were cancelled, moved or under-used, owing to the deployment of ADSL in the territories concerned;

3) an ongoing improvement in the technical offering by the operators (Wi-Fi or satellite) in interaction with the complex forms of demand (peer-to-peer or VoIP). Satellite technical solution are evolving (undoubtedly less quickly than terrestrial solutions), but the commercialisation of offerings using these technologies is to a large extent held back by the difficulty of creating a market that is significantly large market (all the non-covered areas in France) and sustainable (competition with ADSL)

Initially, the project did not provide for bandwidth management, but in a Wi-Fi network, the bandwidth is shared and heavy consumption by one or more network can considerably undermine the quality of the service offered. At the request of the co-ordinators of certain sites, an intelligent bandwidth manager was installed locally. This is based on the prioritisation of the protocols used: the last protocol allocated being peer-to-peer;

4) the wider territorial deployment of the technology beyond the first people taking part in the experiment (waiting lists) and its extension to neighbouring communes.

The experiment has produced in most cases, a surge in local interest in the project by nonparticipating citizens and residents of neighbouring communes. This interest is also boosted by word of mouth, especially as regards the advantageous conditions of the experiment (free, equipment, etc.);

5) improved anticipation by local authorities of the needs of their citizens not only as regards infrastructure needs (reflection on costs, project management, etc.), but also as regards new innovative services (combined with a real territorial strategy) and, finally, in the area of types of usage (taking account of training needs).

In general, these experiments have proved a way of meeting needs expressed and have also helped to mobilise and energise the stakeholders involved locally (public authorities, citizens wanting high-speed access, etc.). As a result, local authorities are considering providing financial support so as not to interrupt the existing connections to increasingly insistent and demanding citizens, at the end of the end of experiments. When one measures the financial effort made and envisaged by small local authorities, even when helped by public co-financing, it is clear that these experiments have satisfied to a large extent the expectations of the territorial stakeholders. 


\section{References}

Bijker, W. E. (1995). Of Bicycles, Bakelites, and Bulbs Toward a Theory of Sociotechnical Change, MIT Press, Cambridge

Bolton P.; Harris C. (1999). Strategic Experimentation. Econometrica, vol.67, n², pp. 349-374

Grossmann, S.J.; Kihlstrom, R.E.; Mirman, L.J. (1977). A Bayesian Approach to the Production of Information and Learning by Doing, Review of Economic Studies, vol. 44, pp. 533-547

Leach, J.C.; Madhavan, A.N. (1993). Price Experimentation and Security Market Structure, The Review of Financial Studies, vol. 6, n², pp. 375-404

Orlikowski, W. (1992). The duality of technology: rethinking the concept of technology in organizations, Organization Science, vol 3, pp. 398-427

Swanson, E.; Ramiller, N.C. (1997). The Organizing Vision in Information System Innovation, Organization Science, vol 8, n5, pp. 458-474

Yin, R.K. (2003). Case study research: Design and methods, $3^{\text {rd }}$ edition, Applied social research methods series, Sage publications, vol. 5, London 


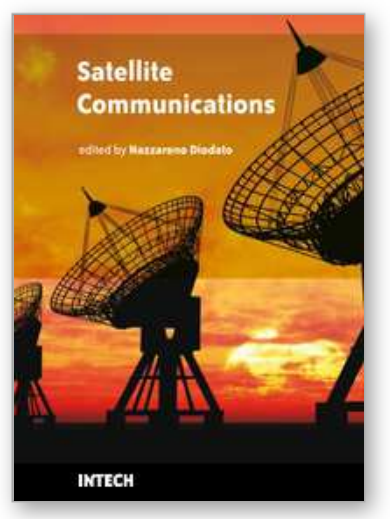

\author{
Satellite Communications \\ Edited by Nazzareno Diodato
}

ISBN 978-953-307-135-0

Hard cover, 530 pages

Publisher Sciyo

Published online 18, August, 2010

Published in print edition August, 2010

This study is motivated by the need to give the reader a broad view of the developments, key concepts, and technologies related to information society evolution, with a focus on the wireless communications and geoinformation technologies and their role in the environment. Giving perspective, it aims at assisting people active in the industry, the public sector, and Earth science fields as well, by providing a base for their continued work and thinking.

\title{
How to reference
}

In order to correctly reference this scholarly work, feel free to copy and paste the following:

Gilles Puel, Valérie Fernandez and Valérie Fautrero (2010). Analysis of Uses and Metrology : an Experiment in Telecommunications by Satellite and Wireless Network Solution for Rural Areas, Satellite Communications, Nazzareno Diodato (Ed.), ISBN: 978-953-307-135-0, InTech, Available from:

http://www.intechopen.com/books/satellite-communications/analysis-of-uses-and-metrology-an-experiment-intelecommunications-by-satellite-and-wireless-network

\section{INTECH}

open science | open minds

\section{InTech Europe}

University Campus STeP Ri

Slavka Krautzeka 83/A

51000 Rijeka, Croatia

Phone: +385 (51) 770447

Fax: +385 (51) 686166

www.intechopen.com

\section{InTech China}

Unit 405, Office Block, Hotel Equatorial Shanghai

No.65, Yan An Road (West), Shanghai, 200040, China

中国上海市延安西路65号上海国际贵都大饭店办公楼 405 单元

Phone: +86-21-62489820

Fax: +86-21-62489821 
(C) 2010 The Author(s). Licensee IntechOpen. This chapter is distributed under the terms of the Creative Commons Attribution-NonCommercialShareAlike-3.0 License, which permits use, distribution and reproduction for non-commercial purposes, provided the original is properly cited and derivative works building on this content are distributed under the same license. 